\title{
Process intensification of the high-purity nitrogen production in twin-bed Pressure Swing Adsorption plants
}

\author{
A. Marcinek ${ }^{1}$ (D) . J. Guderian ${ }^{1} \cdot$ D. Bathen ${ }^{2}$
}

Received: 11 September 2020 / Revised: 16 November 2020 / Accepted: 12 December 2020 / Published online: 23 January 2021

(c) The Author(s) 2021

\begin{abstract}
With increasing nitrogen purity, PSA plants require an over-proportional air demand with the consequence that high-purity PSA systems engender a distinct interest in energy-saving measures. This paper presents process intensification strategies with the focus on a reduced energy consumption. Therefore, the influence of PSA configuration and cycle organisation on process performance was investigated. Results are presented at two product purity levels $\left(10 \mathrm{ppm} / 1000 \mathrm{ppm} \mathrm{O}_{2}\right)$ and two operating temperatures $\left(25^{\circ} \mathrm{C} / 45^{\circ} \mathrm{C}\right)$ in a lab-scale twin bed PSA $(2 \times 2 \mathrm{~L})$. It is shown that dedicated strategies are available to intensify the PSA process; however, their effects are dependent on ambient conditions and product purity levels.
\end{abstract}

Keywords High-purity nitrogen · Nitrogen generation · Pressure swing adsorption $\cdot$ Carbon molecular sieve $\cdot$ Process intensification

\section{Introduction}

At present, the production of nitrogen from the air is carried out mainly by three methods: cryogenic distillation, pressure swing adsorption (PSA), and membrane separation [1]. The selection of a suitable technique is primarily based on the required production rate, load profiles, utilisation (e.g. operating hours per week), and purity level of the product gas. While the operation of cryogenic air separation units (ASUs) is the most efficient method if large amounts of high-purity nitrogen are demanded, the utilisation of membranes would be in preference when the requirement for either quantity and purity is lower. Currently, the PSA technology for nitrogen generation is commercially established in the intermediate area, for product flow rates up to several thousand $\mathrm{Nm}^{3} / \mathrm{h}$

Supplementary Information The online version of this article (https://doi.org/10.1007/s10450-020-00291-8) contains supplementary material, which is available to authorized users.

A. Marcinek

marcinek.aleksandra@fh-muenster.de

1 Department of Chemical Engineering, Muenster University of Applied Sciences, Stegerwaldstrasse 39, 48565 Steinfurt, Germany

2 Department of Thermal Process Engineering, University of Duisburg-Essen, Forsthausweg 2, 47057 Duisburg, Germany (at $0{ }^{\circ} \mathrm{C}, 1 \mathrm{bar}$ abs) and product purity levels up to $10 \mathrm{ppm}$ of the residual oxygen concentration. The process allows the kinetic separation of oxygen from nitrogen which is possible by taking advantage of the remarkably faster sorption rate of oxygen over nitrogen in PSA-plants equipped with carbon molecular sieves (CMS) [2]. High selectivity is attainable due to the sieving effect in intentionally narrowed micropore mouths [3]. The simplicity of the plant operation, together with multiple process variables and cycle organisation strategies, makes the PSA a technology of choice due to an opportunity for customising the system to individual requirements. However, any modification of the cycle organisation or slight alteration of process conditions influences the distribution of driving forces as a function of time within the production and regeneration steps. Any change affects in its ultimate consequence the local gas interstitial velocity which again impacts for instance the local column pressure drop, the heat and mass transfer rate, and the axial dispersion of heat and mass [4].

The compression of air is the key aspect of operating costs while the bed size is the dominating factor in capital costs [5]. Similar to membrane plants, PSA systems require an over-proportional air demand with increasing nitrogen purity. Consequently, the operation of high-purity PSA plants motivates a particular interest in process optimisation with a focus on the reduction of air demand; however, without increasing the number or volume of 
adsorber columns. That is why research aimed to intensify the process and thus increase the cost-effective applicability of the $\mathrm{N}_{2}$-PSA technology in the high-purity range could reduce the impact on the natural environment since it utilises significantly less energy, hence generates less greenhouse gas than cryogenic air distillation [6].

Moulijn and Stankiewicz defined process intensification as "any chemical engineering development that leads to a substantially smaller, cleaner, safer, and more energy-efficient technology" [7]. Thus, very different measures can be considered for intensifying PSA processes, including the application of improved separation materials as well as the configuration of the installation. Related thoughts are e.g. multi-bed PSA systems [8], trim feed concepts [9], dual-reflux concepts [10], hybrid systems [11], or opting for vacuum-PSA (VPSA) instead of PSA systems. Additionally, if the product gas is required on the low-pressure level, the recovery of pressure energy from the product stream by microturbines coupled with electric power generators is also a potential development. Also, the particle diameter can play a significant role as a measure for intensifying processes-depending on the mass transfer controlling steps from bulk to particle internal adsorption sites for the considered adsorbent [12]. However, in practice particularly the pressure drop is also influenced by the particle diameter, so that the minimal, respectively optimal particle diameter also depends on the possibility to achieve the striven adsorption pressure in the production step which becomes the more difficult the bigger the adsorbers.

Unfortunately, many of the listed concepts are not feasible in high-purity $\mathrm{N}_{2}$-PSA plants since the commercially established nitrogen productivity range of a maximum few thousand $\mathrm{Nm}^{3} / \mathrm{h}$ makes those approaches not affordable so far. That is why in the presented work process intensification focuses on already available measures, optimising primarily the plant configuration and the process cycle organisation. As a constraint the separation material is fixed which means that the particle diameter is fixed in this study as well.

After all, a PSA set-up is considered, consisting of two single adsorber columns which are alternating between adsorption and desorption modes, providing a semi-continuous flow of a high-pressure nitrogen stream [13]. Effect of (1) the flow resistances in the piping system including the trim of equalisation streams, (2) the nitrogen receiver volume, (3) the system void volumes, (4) the purge stream flow rate, (5) the half-cycle time, and (6) the adoption of a cutting step on the separation process performance are experimentally studied for the high-purity $\mathrm{N}_{2}$-PSA at different product purity levels and operating temperatures. Recommendations for process intensification strategies particularly relevant to industrial-scale applications are presented and discussed.

\section{Experimental}

The scheme of the experimental set-up is presented in Fig. 1. Three main sections can be recognised: the feed gas preparation and pre-treatment section (a), the twin-bed PSA plant section (b), and the product and tail-gas analytics section (c). Details of the unit as well as the properties of adsorbent and adsorber column are described in the supplementary information and elsewhere [14]. The unit is fed with dry air under a pressure of 8.1 bar abs. The adsorption process is performed at a working pressure of 8 bar abs. To control the purity level always the product stream flow rate is adjusted in the experiments. This control strategy represents the common operation of commercial plants. The flow rate of counter-current purge stream equals $0.0485 \mathrm{Nm}^{3} / \mathrm{h}$, which corresponds to the $40 \%$ fraction of the adsorber volume within the selected purge time. The process comprises a six-step PSA cycle which consists of (1) co- and counter-current bed pressure equalisation; (2) cocurrent pressurisation by feed with (3) counter-current backflow of productf; (4) production; (1) co- and counter-current bed pressure equalisation; (5) counter-current blow-down; and (6) counter-current purge by the product gas. Details of the PSA process organisation are described elsewhere [14]. The scheme of the six-step cycle design is presented in the supplementary information.

\section{PSA performance indicators}

The most common performance indicators (PIs) for the $\mathrm{N}_{2}$-PSA technology are the product purity, the productivity, and the air demand. In this study, process PIs are derived from macroscopic material balances of the PSA-unit presented in Eqs. 1 and 2. Therefore, productivity and air demand are calculated according to Eqs. 3 and 4, respectively, where Q is the stream flow rate $\left(\mathrm{Nm}^{3} / \mathrm{h}\right), \rho$ is the gas density $\left[\mathrm{kg} / \mathrm{Nm}^{3}\right], \mathrm{w}_{\mathrm{O} 2}$ is the oxygen mass fraction in the gas [mass.- $\%$ ], and $\mathrm{V}_{\mathrm{CMS}}$ is the volume of adsorbent in the system $\left[\mathrm{m}^{3}\right]$. Detailed definitions, determination, and verification strategy of PIs are described elsewhere [14]. In the $\mathrm{N}_{2}$-PSA technology it is accepted that the product purity comprises the content of both nitrogen and argon since many industrial applications do not require an additional separation of inert gas mixtures. Consequently, the determination of the product purity is performed by assuming a binary gas mixture where simply the difference to the oxygen concentration results in the nitrogen purity.

$Q_{\text {feed }} \cdot \rho_{\text {feed }}=Q_{\text {product }} \cdot \rho_{\text {product }}+Q_{\text {tail-gas }} \cdot \rho_{\text {tail-gas }}$ 


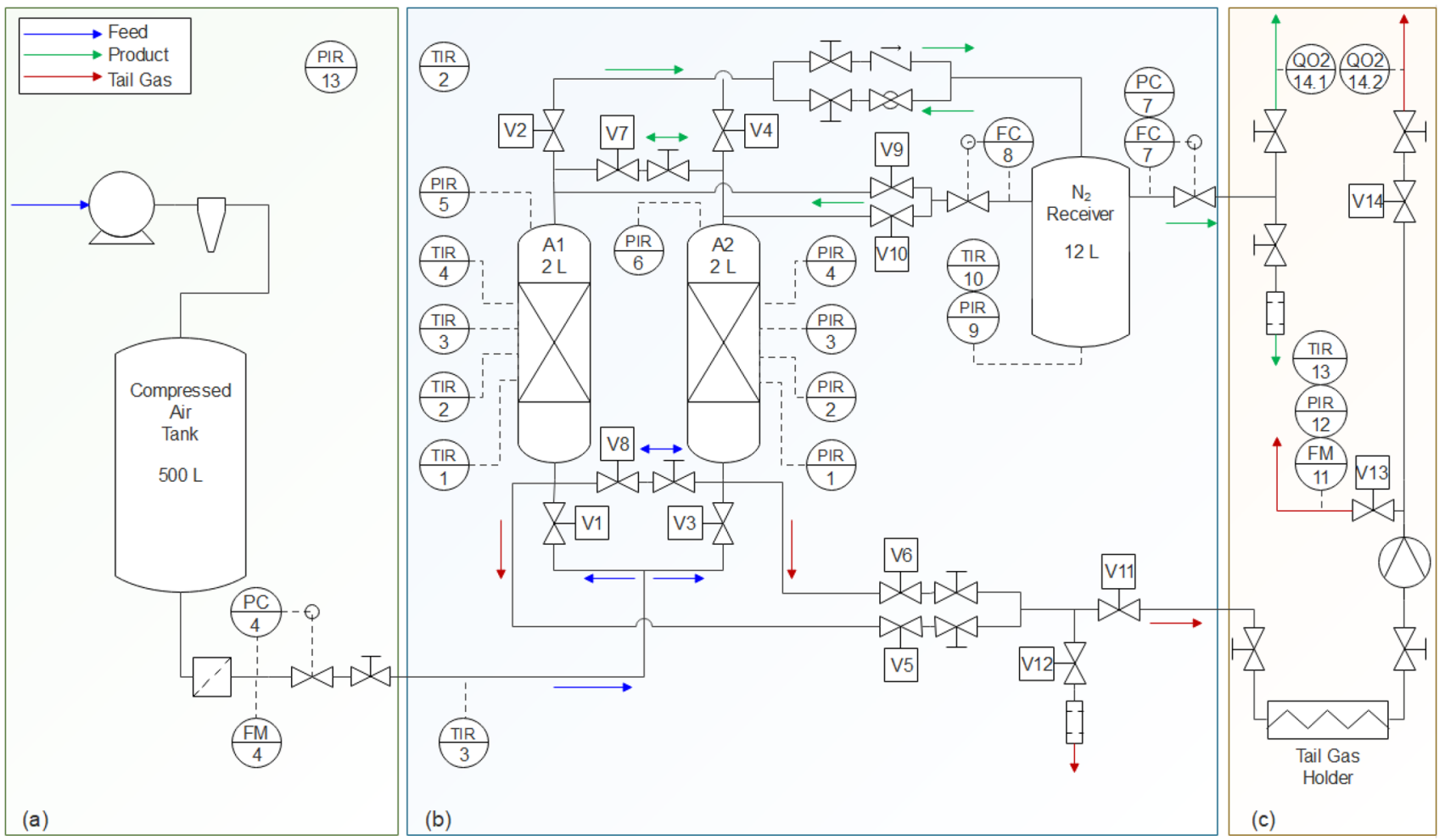

Fig. 1 Scheme of the PSA experimental set-up [14]

$Q_{\text {feed }} \cdot \rho_{\text {feed }} \cdot w_{O_{2} \text { feed }}=Q_{\text {product }} \cdot \rho_{\text {product }} \cdot w_{O_{2} \text { product }}$

$$
+Q_{\text {tail-gas }} \cdot \rho_{\text {tail-gas }} \cdot w_{\mathrm{O}_{2} \text { tail-gas }}
$$

$$
\begin{aligned}
\frac{Q_{\text {product }}}{V_{C M S}}= & \frac{\left(Q_{\text {feed }} \cdot \rho_{\text {feed }}-Q_{\text {tail-gas }} \cdot \rho_{\text {tail-gas }}\right)}{V_{C M S} \cdot \rho_{\text {product }}} \\
& =\frac{\left(Q_{\text {feed }} \cdot \rho_{\text {feed }} \cdot w_{O_{2} \text { feed }}-Q_{\text {tail-gas }} \cdot \rho_{\text {tail-gas }} \cdot w_{O_{2} \text { tail-gas }}\right)}{V_{C M S} \cdot \rho_{\text {product }} \cdot w_{O_{2} \text { product }}}
\end{aligned}
$$

$$
\begin{aligned}
& \frac{Q_{\text {feed }}}{Q_{\text {product }}}=\frac{\rho_{\text {product }}}{\rho_{\text {feed }}}+\frac{Q_{\text {tail-gas }} \cdot \rho_{\text {tail-gas }}}{Q_{\text {product }} \cdot \rho_{\text {feed }}} \\
& =\frac{\rho_{\text {product }} \cdot w_{\mathrm{O}_{2} \text { product }}}{\rho_{\text {feed }} \cdot w_{\mathrm{O}_{2} \text { feed }}}+\frac{Q_{\text {tail-gas }} \cdot \rho_{\text {tail-gas }} \cdot w_{\mathrm{O}_{2} \text { tail-gas }}}{Q_{\text {product }} \cdot \rho_{\text {feed }} \cdot w_{\mathrm{O}_{2} \text { feed }}}
\end{aligned}
$$

\section{Results and discussion}

\subsection{Effect of flow resistances in the piping system}

Since the rates of pressure build-up and fall-off appoint the main driving forces of adsorption and desorption during the PSA cyclic operation, the issue of pressure drop in the system comes to the fore when optimising the process performance. Generally, there are three sources of pressure drop in the installation: (1) uncontrolled flow resistances in the piping system, e.g. pipes, bends, in-line filters, connectors, or adsorber column elements as perforated plates or sieves for the packed-bed support; (2) controlled flow resistances in the piping system, i.e. the control valves installed for a flow rate regulation of particular streams; and (3) the adsorbent fixed-bed. All of these factors must be taken into account when aiming for the optimisation of process performance. Whereas the column dimensions and armatures together with the size of the adsorbent pellets are selected at the plant design stage, the performance of already existing PSA plants can still be improved by the proper adjustment of controlled flow resistances in the piping system. Therefore, the effect of the regulation of controlled flow resistances in the piping system on performance indicators, i.e. productivity and air demand, was investigated for a PSA process exhibiting cycle conditions as presented in Table 1. Selected operating temperature levels are in agreement with the vast majority of relevant industrial applications; however, lower temperatures are also common. Thus, certain deviations in PSA 
Table 1 Standardised cycle conditions of the experimental program

\begin{tabular}{ll}
\hline Product purity $\left[\mathrm{ppm} \mathrm{O}_{2}\right]$ & $10 ; 1000$ \\
Operating pressure $(\mathrm{bar}$ abs $)$ & 8 \\
Operating temperature $\left({ }^{\circ} \mathrm{C}\right)$ & $20 ; 45$ \\
Half-cycle time $(\mathrm{s})$ & 60 \\
Adsorption time/desorption time (s) & 59 \\
Equalisation time (s) & 1 \\
Equalisation strategy & Top/ \\
& Top + Bot- \\
& tom/Bot- \\
Purge time (s) & tom \\
Purge flow rate $\left(\mathrm{Nm}^{3} / \mathrm{h}\right)$ & 59 \\
Backflow & 0.0485 \\
\hline
\end{tabular}

Table 2 PSA performance in various controlled flow resistances in the piping system at $20^{\circ} \mathrm{C}$

\begin{tabular}{llll}
\hline & $\begin{array}{l}\text { Stem position } \\
\text { Opening }(\%)\end{array}$ & $\begin{array}{l}\text { Productivity } \\
\left(\mathrm{Nm}^{3} / \mathrm{h} \mathrm{N}_{2} /\right. \\
\left.\mathrm{m}^{3} \mathrm{CMS}\right)\end{array}$ & $\begin{array}{l}\text { Air demand } \\
\left(\mathrm{Nm}^{3} / \mathrm{h} \text { air/ }\right. \\
\left.\mathrm{Nm}^{3} / \mathrm{h} \mathrm{N}_{2}\right)\end{array}$ \\
\hline Feed pipeline & 100 & 80.67 & 3.49 \\
& 72 & 82.60 & 3.40 \\
& $53 *$ & 83.04 & 3.39 \\
& 34 & 82.60 & 3.42 \\
Tail-gas pipeline & 25 & 81.92 & 3.44 \\
& 15 & 81.72 & 3.45 \\
& 6 & 80.13 & 3.49 \\
& $100^{*}$ & 80.67 & 3.49 \\
& 81 & 80.67 & 3.51 \\
& 53 & 80.03 & 3.53 \\
& 25 & 74.87 & 3.62 \\
& 15 & 67.15 & 3.85 \\
& 100 & 80.67 & 3.49 \\
& 75 & 83.50 & 3.41 \\
& 50 & 89.65 & 3.22 \\
& $25 *$ & 94.71 & 3.19 \\
& 5 & 95.37 & 3.39 \\
\hline
\end{tabular}

*Favourable stem position

performance results are expected at dissimilar operating temperature levels, mostly due to modified conditions of a mass transfer in adsorbent micropores.

As a reference, the process with minimised controlled flow resistances in the PSA unit was selected. In order to do so, control valves in all investigated pipelines-the feed, the tail-gas, and the equalisation pipelines-were fully opened, and the performance indicators were determined. Subsequently, the flow resistance in each mentioned pipeline was examined individually by adjusting the control valve stem position, whilst all other control valves were returned to the reference state. Regarding the equalisation valves both regulators in the equalisation pipelines (Top + Bottom) were operated symmetrically. All mentioned control valves assembled in the PSA test unit are commercially available throttles or shut-off needle valves. The favourable stem position of each control valve was found based on the PSA performance indicators results at product purity of $1000 \mathrm{ppm} \mathrm{O}_{2}$ at $20{ }^{\circ} \mathrm{C}$ which are presented in Table 2 and Fig. 2. In accordance with a current global focus on the energy conservation issue, a minimised air demand, rather than maximised productivity, designates the preferable process outcome.

As demonstrated in Fig. 2, controlled flow resistances in the piping system have an evident impact on the dynamic behaviour of the PSA system and therefore a significant effect on the process performance. The control valve in the feed pipeline mainly regulates the volume ratio of the cocurrent feed and counter-current backflow streams in the adsorber column during the pressurisation step. As shown in Fig. 2a, the favourable stem position was found at an opening of $53 \%$. This indicates an optimal amount of product gas reversed to the system as a backflow-not excessive to decrease the productivity, and not insufficient to slow down the pressure build-up in the system or to cause a premature adsorber breakthrough due to dispersion effects. When adjusting the feed control valve to the favourable stem position, the productivity increases by $2.94 \%$ and the air demand decreases by $2.86 \%$ in relation to the reference process.

Considering the tail-gas pipeline in Fig. 2b, it is shown that any increase of the flow resistance causes a declined PSA performance due to the reduction of the driving force for the desorption process, resulting in a deterioration of the fixed-bed regeneration.

The pressure equalisation step is introduced to the cycle mainly for the reduction of operating costs since already compressed and purified air can be transferred partly to the neighbour column. Control valves in pressure equalisation pipelines (Top + Bottom) regulate the volume of gas exchanged between the both columns during the equalisation step, as well as the subsequent starting pressure for pressurisation and blow-down steps, respectively. Since it acts as an idle period during the PSA operation, the time of the pressure equalisation step should remain as short as possible. It is expected that the complete pressure alignment to the arithmetic average level, by minimising the flow resistance, would lead to the minimal air demand. However, during the rapid pressure reduction in the high-pressure column a simultaneous desorption of the fast-adsorbing gas takes place. Thus, the desorbed oxygen is eventually transferred into the low-pressure column, contaminating the previously regenerated adsorbent. Consequently, the adsorption capacity in the following production step is declined. For this reason, the optimum position of stems was found at $25 \%$ 

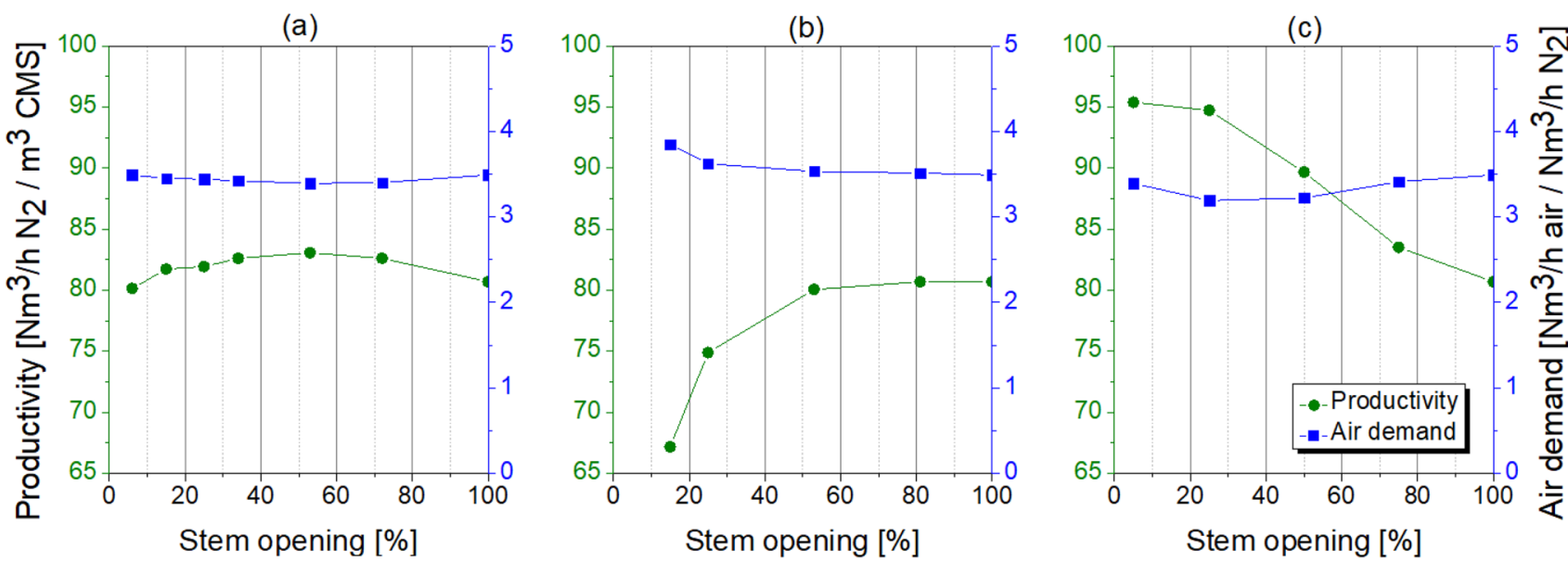

Fig. 2 PSA performance at various controlled flow resistances in the piping system: a feed pipeline, $\mathbf{b}$ tail-gas pipeline, $\mathbf{c}$ equalisation pipelines

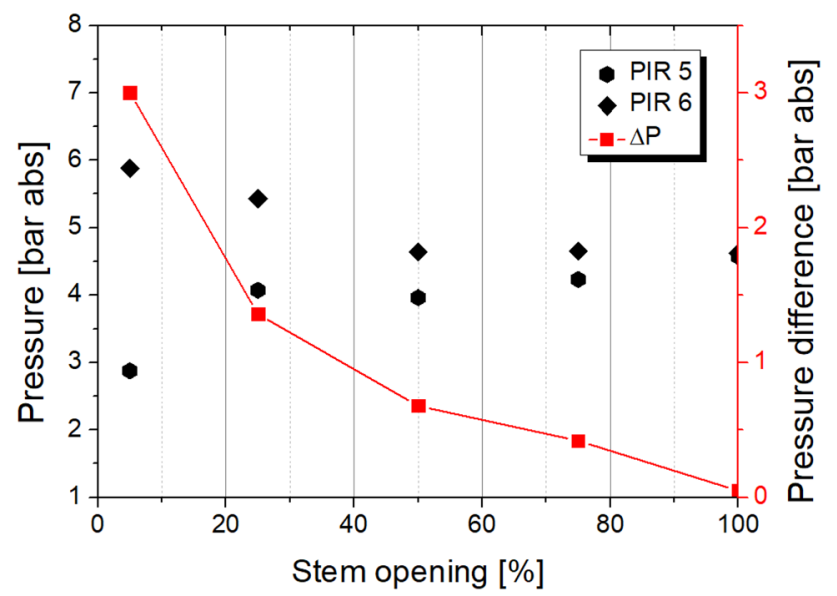

Fig. 3 Pressure in the adsorber columns after pressure equalisation at different stem positions of the equalisation valves opening, as presented in Fig. 2c. When adjusting equalisation control valves to the favourable stem position, the productivity increases by $18.22 \%$ and the air demand decreases by $8.60 \%$ in relation to the reference process. The pressure measured at the top of the adsorber columns after pressure equalisation is presented in Fig. 3. The diagram shows that a remaining pressure difference of about 1.36 bar between the columns after equalisation results in the optimal PSA performance in this plant.

Finally, control valves in all investigated pipelines were adjusted according to their individual favourable stem opening. PSA performance indicators were determined at different product purity levels as well as in different operating temperatures and compared to those of the reference process. The results are presented in Tables 3 and 4. Optimisation of controlled flow resistances performed by setting the stem position of discussed control valves to their
Table 3 PSA performance with minimised and optimised controlled flow resistances in the piping system at product purity of $1000 \mathrm{ppm} \mathrm{O}_{2}$
Table 4 PSA performance with minimised and optimised controlled flow resistances in the piping system at product purity of $10 \mathrm{ppm} \mathrm{O}_{2}$

\begin{tabular}{lllllll}
\hline & $\begin{array}{l}\text { Minimised con- } \\
\text { trolled flow resist- } \\
\text { ances }\end{array}$ & $\begin{array}{l}\text { Optimised controlled } \\
\text { flow resistances }\end{array}$ & Increment (\%) \\
\hline Operating temperature $\left({ }^{\circ} \mathrm{C}\right)$ & 20 & 45 & 20 & 45 & 20 & 45 \\
Productivity $\left(\mathrm{Nm}^{3} / \mathrm{h} \mathrm{N}_{2} / \mathrm{m}^{3} \mathrm{CMS}\right)$ & 80.65 & 68.17 & 97.35 & 85.87 & 20.71 & 25.96 \\
Air demand $\left(\mathrm{Nm}^{3} / \mathrm{h}^{\text {air }} / \mathrm{Nm}^{3} / \mathrm{h} \mathrm{N}_{2}\right)$ & 3.49 & 4.27 & 3.18 & 3.77 & -8.88 & -11.71 \\
\hline
\end{tabular}

\begin{tabular}{lllllcc}
\hline & \multicolumn{2}{l}{$\begin{array}{l}\text { Minimised con- } \\
\text { trolled flow resist- } \\
\text { ances }\end{array}$} & $\begin{array}{l}\text { Optimised con- } \\
\text { trolled flow resist- } \\
\text { ances }\end{array}$ & Increment (\%) \\
\hline Operating temperature $\left({ }^{\circ} \mathrm{C}\right)$ & 20 & 45 & 20 & 45 & 20 & 45 \\
Productivity $\left(\mathrm{Nm}^{3} / \mathrm{h} \mathrm{N}_{2} / \mathrm{m}^{3} \mathrm{CMS}\right)$ & 12.67 & 11.25 & 29.64 & 19.80 & 133.94 & 76.00 \\
Air demand $\left(\mathrm{Nm}^{3} / \mathrm{h} \mathrm{air}^{3} / \mathrm{Nm}^{3} / \mathrm{h} \mathrm{N}_{2}\right)$ & 15.93 & 20.72 & 7.78 & 12.73 & -51.16 & -38.56 \\
\hline
\end{tabular}


Table 5 Effect of the asymmetric pressure equalisation on the PSA performance at product purity of $1000 \mathrm{ppm} \mathrm{O}_{2}$

\begin{tabular}{llll}
\hline $\begin{array}{l}\text { Pressure equalisation Top/ } \\
\text { Top + Bottom/Bottom }\end{array}$ & $\begin{array}{l}\text { Stem position opening } \\
(\%)\end{array}$ & $\begin{array}{l}\text { Productivity }\left(\mathrm{Nm}^{3} / \mathrm{h} \mathrm{N}_{2} /\right. \\
\left.\mathrm{m}^{3} \mathrm{CMS}\right)\end{array}$ & $\begin{array}{l}\text { Air demand } \\
\left(\mathrm{Nm}^{3} / \mathrm{h} \text { air/ }\right. \\
\left.\mathrm{Nm}^{3} / \mathrm{h} \mathrm{N}_{2}\right)\end{array}$ \\
\hline $0+1$ & $0+100$ & - & - \\
$\frac{1}{3}+\frac{2}{3}$ & $12.5+37.5$ & 84.50 & 3.47 \\
$\frac{1}{2}+\frac{1}{2}$ & $25+25$ & 97.35 & 3.18 \\
$\frac{2}{3}+\frac{1}{3} *$ & $37.5+12.5$ & 99.15 & 3.13 \\
$1+0$ & $100+0$ & 84.25 & 3.52 \\
\hline
\end{tabular}

*Favourable pressure equalisation strategy
Table 6 Effect of the asymmetric pressure equalisation on the PSA performance at product purity of $10 \mathrm{ppm} \mathrm{O}_{2}$

\begin{tabular}{|c|c|c|c|}
\hline $\begin{array}{l}\text { Pressure equalisa- } \\
\text { tion } \\
\text { Top/Top + Bot- } \\
\text { tom/Bottom }\end{array}$ & $\begin{array}{l}\text { Stem position } \\
\text { Opening }(\%)\end{array}$ & $\begin{array}{l}\text { Productivity } \\
\left(\mathrm{Nm}^{3} / \mathrm{h} \mathrm{N}_{2} / \mathrm{m}^{3}\right. \\
\text { CMS })\end{array}$ & $\begin{array}{l}\text { Air } \\
\text { demand } \\
\left(\mathrm{Nm}^{3} / \mathrm{h}\right. \\
\text { air } / \mathrm{Nm}^{3} / \mathrm{h} \\
\left.\mathrm{N}_{2}\right)\end{array}$ \\
\hline $0+1$ & $0+100$ & - & - \\
\hline$\frac{1}{3}+\frac{2}{3}$ & $12.5+37.5$ & 22.40 & 9.83 \\
\hline$\frac{1}{2}+\frac{1}{2} *$ & $25+25$ & 29.64 & 7.78 \\
\hline$\frac{2}{3}+\frac{1}{3}$ & $37.5+12.5$ & 25.70 & 8.65 \\
\hline $1+0$ & $100+0$ & - & - \\
\hline
\end{tabular}

*Favourable pressure equalisation strategy

individually-established favourable position enhanced the PSA performance at every considered process condition; however, the effect becomes more significant as the product purity increases. In spite of that, to demonstrate the overall optimum of PSA performance indicators in the function of the controlled flow resistances regulation in the piping system, a multi-parameter optimisation should be executed.

Additionally, the trim of the both top and bottom equalisation control valves has been investigated, whilst other control valves have remained in their individual optimum position of the stem. The effect on the PSA performance of the asymmetric settings was considered at $20{ }^{\circ} \mathrm{C}$. The results are presented in Tables 5 and 6 . In the case of pressure equalisation exclusively through the bottom equalisation pipeline the targeted oxygen residual concentration in the product gas could not be accomplished at both investigated product purity levels; likewise, whilst the pressure equalisation exclusively through the top pipeline at high product purity level.

At the product purity of $1000 \mathrm{ppm}_{2}$ the favourable pressure equalisation strategy proved to be an asymmetric setting with a $2 / 3$ of the gas transferred through the top equalisation pipeline and a $1 / 3$ through the bottom one. By means of this strategy the productivity increases by $22.94 \%$ and the air demand decreases by $10.32 \%$ in relation to the reference process. However, at the product purity of $10 \mathrm{ppm} \mathrm{O}_{2}$, the favourable pressure equalisation strategy maintained to be a symmetric setting of equalisation control valves.

The observed effect is directly related to the development of the mass transfer zone (MTZ) within the adsorbent fixedbed in the cyclic steady state (CSS) conditions which can be tracked via the measurement of temperature alteration during the production step; assuming that the propagation velocity of the temperature front is not higher than of the concentration front. Because the PSA experimental unit can be considered as a non-adiabatic system, the formation of a pure thermal wave front as described by Pan and Basmadjian [15] will not occur. The experimental temperature profiles at investigated product purity levels are presented in Fig. 4.

At low product purity the gas velocity in the packed-bed is relatively high so that the MTZ becomes elongated due to mass dispersion effects. In that case, an increase of the flow resistance in the bottom equalisation pipeline reduces the driving force for the desorption process which results in the minor transfer of the highly oxygen-enriched gas into the bottom part of the neighbour column, and thus, the adsorption capacity in the subsequent production step is not harmfully affected. Moreover, the appropriate adjustment of the flow resistance in the top equalisation pipeline allows the straightforward transfer of the highly purified nitrogen gas into the top part of the neighbour column which supports the subsequent backflow stream.

On the other hand, at high product purity, the gas velocity in the packed-bed is relatively low and the mass transfer occurs mainly in the bottom part of the adsorbent fixed-bed. In that case, the top part of the bed serves as the nitrogen safeguard bulk that ensures nearly complete oxygen rejection from the compressed air feed stream. The symmetric setting of equalisation control valves results in the highest performance, since the top part of both adsorber columns is not contacted with oxygen-enriched gas-neither in co- or counter-current pressure equalisation stream, so the nitrogen safeguard bulk is not harmfully affected. The graphical representation of the MTZ with related favourable pressure equalisation strategies at investigated product purity levels is introduced in Fig. 5. These results motivate a more realistic 

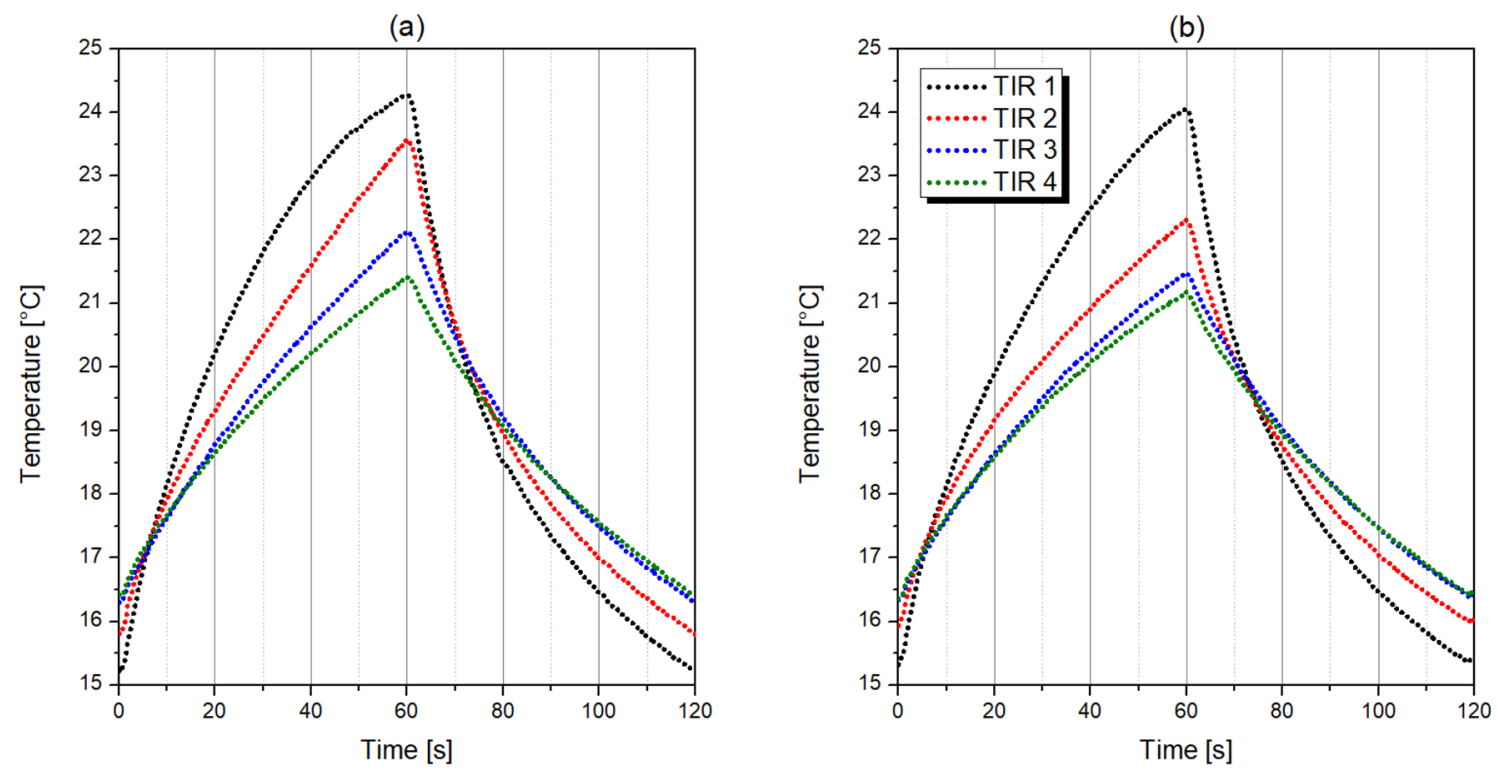

Fig. 4 Experimental temperature profiles along the adsorbent fixed-bed at $20{ }^{\circ} \mathrm{C}$ : a at product purity of 1000 ppm $\mathrm{O}_{2}$, b at product purity of $10 \mathrm{ppm} \mathrm{O}_{2}$

(a)

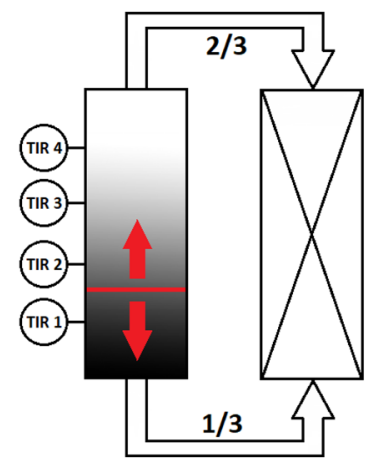

Fig. 5 Visual demonstration of the oxygen MTZ development with related favourable pressure equalisation strategy: a at product purity of $1000 \mathrm{ppm} \mathrm{O}_{2}$, $\mathbf{b}$ at product purity of $10 \mathrm{ppm} \mathrm{O}_{2}$

(b)

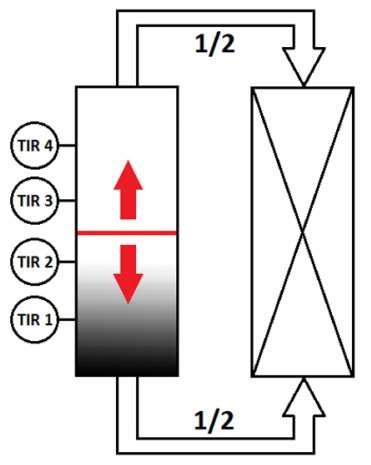

Table 7 PSA performance at different volume ratios of the $\mathrm{N}_{2}$-receiver tank to the adsorber column at product purity of $1000 \mathrm{ppm} \mathrm{O}_{2}$

Table 8 PSA performance at different volume ratios of the $\mathrm{N}_{2}$-receiver tank to the adsorber column at product purity of $10 \mathrm{ppm} \mathrm{O}_{2}$

\begin{tabular}{lllllll}
\hline $\mathrm{V}_{\text {receiver }} / \mathrm{V}_{\text {adsorber }}$ & 6 & & 3.5 & \multicolumn{3}{c}{2.5} \\
\hline Operating temperature $\left({ }^{\circ} \mathrm{C}\right)$ & 20 & 45 & 20 & 45 & 20 & 45 \\
Productivity $\left(\mathrm{Nm}^{3} / \mathrm{h} \mathrm{N}_{2} / \mathrm{m}^{3} \mathrm{CMS}\right)$ & 97.35 & 85.87 & 95.00 & 84.75 & 92.80 & 83.45 \\
Air demand $\left(\mathrm{Nm}^{3} / \mathrm{h}\right.$ air $\left./ \mathrm{Nm}^{3} / \mathrm{h} \mathrm{N}_{2}\right)$ & 3.18 & 3.77 & 3.22 & 3.82 & 3.27 & 3.88 \\
\hline
\end{tabular}

\begin{tabular}{lllllll}
\hline $\mathrm{V}_{\text {receiver }} / \mathrm{V}_{\text {adsorber }}$ & 6 & & 3.5 & \multicolumn{3}{l}{2.5} \\
\hline Operating temperature $\left({ }^{\circ} \mathrm{C}\right)$ & 20 & 45 & 20 & 45 & 20 & 45 \\
Productivity $\left(\mathrm{Nm}^{3} / \mathrm{h} \mathrm{N}_{2} / \mathrm{m}^{3} \mathrm{CMS}\right)$ & 29.64 & 19.80 & 25.47 & 15.90 & 22.82 & 12.80 \\
Air demand $\left(\mathrm{Nm}^{3} / \mathrm{h}\right.$ air $\left./ \mathrm{Nm}^{3} / \mathrm{h} \mathrm{N}_{2}\right)$ & 7.78 & 12.73 & 8.84 & 15.45 & 9.65 & 18.85 \\
\hline
\end{tabular}

simulation of mass transfer effects in PSA adsorbers as being state-of-the-art today and the subject of further studies by the authors in the near future.

The subsequent experiments presented in this paper were performed in the condition of optimised controlled flow resistances with the symmetric operation of equalisation control valves.

\subsection{Effect of the volume of the $\mathrm{N}_{2}$-receiver tank}

The $\mathrm{N}_{2}$-receiver tank is implemented in the PSA system in order to operate the cyclic process with a constant flow rate of a high-pressure nitrogen stream that is requested in the majority of industrial applications. Moreover, a mixing space for the product gas is provided which is generated during the production step at inconstant composition. In this 

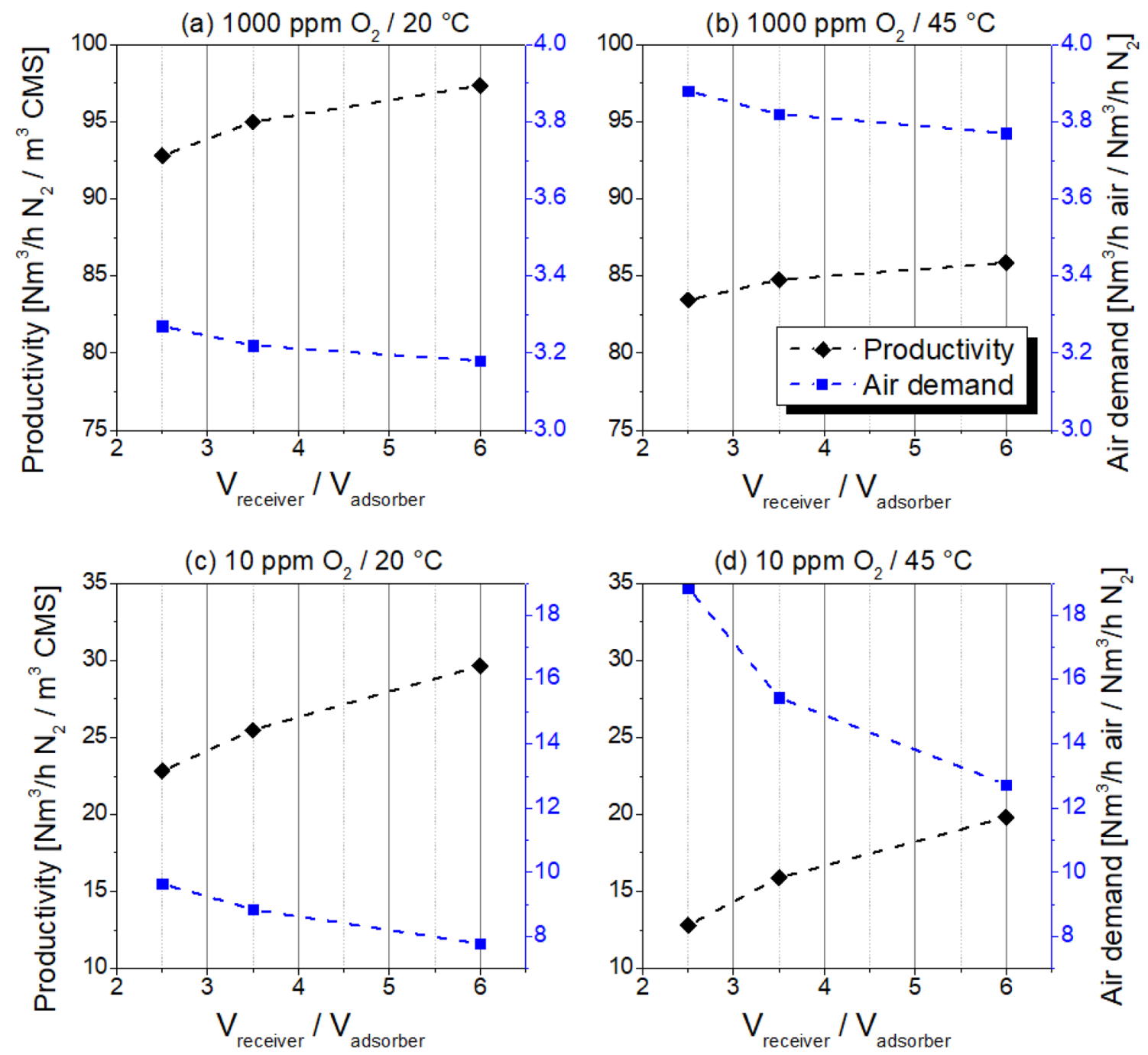

Fig. 6 PSA performance in different volume ratio of the $\mathrm{N}_{2}$-receiver tank to the adsorber column: $\mathbf{a}$, $\mathbf{b}$ at product purity of $1000 \mathrm{ppm} \mathrm{O}_{2}, \mathbf{c}, \mathbf{d}$ at product purity of $10 \mathrm{ppm} \mathrm{O}_{2}, \mathbf{a}, \mathbf{c}$ in operating temperature of $20^{\circ} \mathrm{C}, \mathbf{b}, \mathbf{d}$ in operating temperature of $45^{\circ} \mathrm{C}$

Table 9 Alteration of the PSA performance at reduced volume ratios of $\mathrm{N}_{2}$-receiver tank to adsorber column

\begin{tabular}{lllllllll}
\hline Product purity level $\left[\mathrm{ppm} \mathrm{O}_{2}\right]$ & 10 & & \multicolumn{5}{c}{1000} \\
Operating temperature $\left({ }^{\circ} \mathrm{C}\right)$ & 20 & & 45 & & 20 & 45 & \\
Reduction of $\mathrm{V}_{\text {receiver }} / \mathrm{V}_{\text {adsorber }}(\%)$ & 42 & 58 & 42 & 58 & 42 & 58 & 42 & 58 \\
Increment of productivity (\%) & -14.07 & -23.01 & -19.70 & -35.35 & -2.41 & -4.67 & -1.30 & -2.82 \\
Increment of air demand $(\%)$ & 13.62 & 24.04 & 21.37 & 48.08 & 1.26 & 2.83 & 1.33 & 2.92 \\
\hline
\end{tabular}

test rig also the purge and the backflow streams directed to the adsorber columns are served from the $\mathrm{N}_{2}$-receiver tank. The selection of the smallest possible buffer vessel is of essential importance while aiming for a reduction of the unit footprint. However, an insufficient volume of the tank would give rise to enlarged pressure differences in the system and could be a reason for reduced unit performance. Thus, the effect of the volume ratio of the product buffer vessel to the adsorber column on PSA performance indicators was experimentally studied by replacing the existing tank by smaller tanks. The results are presented in Tables 7 and 8 and Fig. 6. The increments of performance indicators associated with the change of the volume ratio of the $\mathrm{N}_{2}$-receiver to the adsorber column are displayed in Table 9.

During the PSA operation, the pressure maintained in the $\mathrm{N}_{2}$-receiver directly affects the gas flow rate through the adsorbent fixed-bed which consequently influences the mass transfer conditions especially in the case of kinetically 
(a)

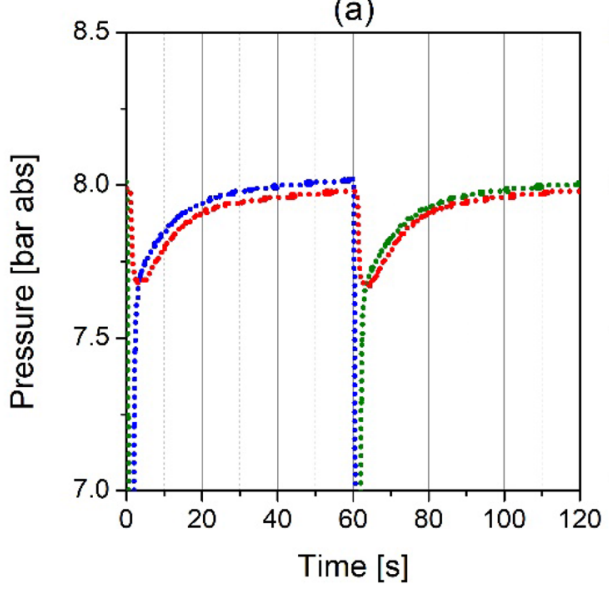

(b)

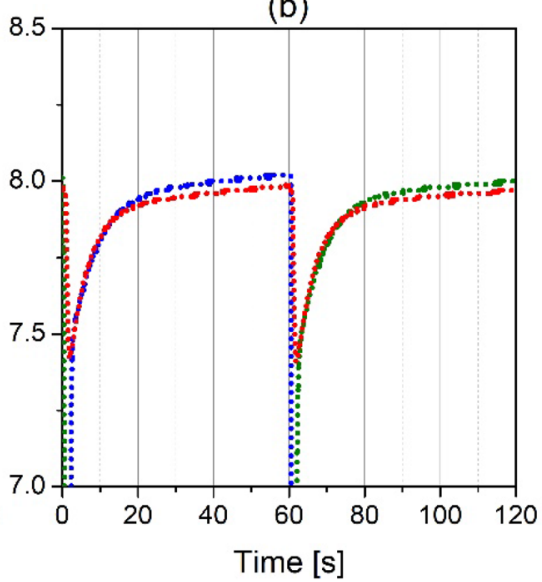

(c)

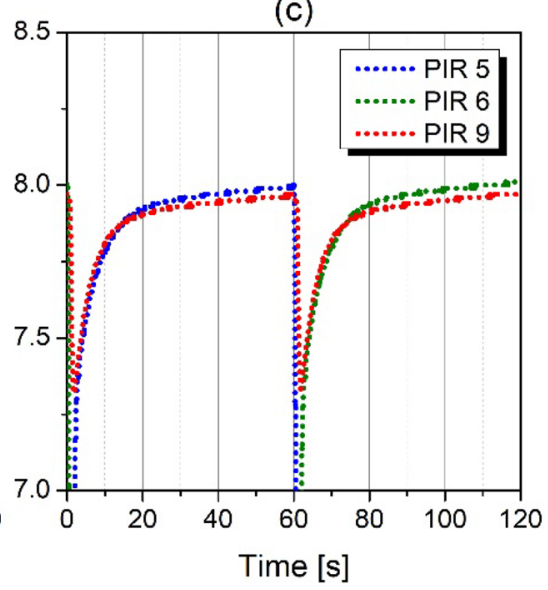

Fig. 7 Experimental pressure profiles of adsorber columns and $\mathrm{N}_{2}$-receiver tank at different $\mathrm{V}_{\text {receiver }} / \mathrm{V}_{\text {adsorber }}$ : a 6 , b 3.5 , c 2.5

controlled separations. The experimental pressure profiles of adsorbers and product buffer tank at different volume ratios of the $\mathrm{N}_{2}$-receiver to the adsorber column are presented in Fig. 7. As a consequence of the co-current pressurisation of the adsorbent fixed-bed with a simultaneous counter-current backflow of product, the pressure in the $\mathrm{N}_{2}$-receiver tank declines at the beginning of the PSA cycle. That pressure downfall becomes more extensive as the volume of the product buffer tank is reduced. An increased pressure difference between the adsorber column and the $\mathrm{N}_{2}$-receiver is created which causes an enlarged gas velocity in the adsorbent fixedbed and therefore a decreased contact time of gas and solid phases. Moreover, the final production pressure is achieved in the adsorber column with a significant delay, diminishing the adsorption process efficiency. Therefore, at every investigated process condition the reduction of the volume ratio of the $\mathrm{N}_{2}$-receiver tank to the adsorber column results in lower nitrogen productivity and higher air demand.

However, the reduction of the product buffer vessel volume is recommended when low purity nitrogen is required. In this case, the gas velocity in the packed column is already relatively high so that its further increase caused by the enlarged pressure difference between the adsorber column and the $\mathrm{N}_{2}$-receiver tank has not a great impact on the mass transfer dynamics. At both investigated operating temperature levels, the modification between highest and lowest volume ratio of $\mathrm{N}_{2}$-receiver to adsorber column causes a decrease in productivity and an increase in air demand merely by $5 \%$ and $3 \%$, respectively. On the other hand, the generation of nitrogen at a high purity level demands a product buffer vessel of large volume. In this case every acceleration of the gas within the adsorber causes an enlargement of the mass transfer zone; thus, the premature breakthrough of oxygen. Especially at high operating temperature, the modification between highest and lowest volume ratio of
$\mathrm{N}_{2}$-receiver to adsorber column causes a decrease of the productivity and an increase in the air demand by nearly $35 \%$ and $50 \%$, respectively, which is unacceptable for an industrial PSA operation.

\subsection{Effect of the void volumes in the PSA system}

The PSA void volumes can be generally classified into three categories: (1) packed-bed void volume, characterised by the parameter of bed porosity which usually includes voids between adsorbent particles in the bulk of the fixed-bed as well as voids between adsorbent particles and column walls alongside the adsorber; (2) adsorber void volume which is the column volume not occupied by the adsorbent, commonly the armature or fittings components supporting the packed-bed e.g. perforated plates, sieves, stabilising rings, ceramic balls, coconut mats etc.; and (3) non-adsorber void volume, associated with assembled elements exterior to the adsorber column which is essentially volume of the piping, but also other elements, e.g. installed in-line filters. Since the packed-bed void has the most significant impact on the product purity level and thus productivity [16], the adsorber and non-adsorber voids could notably influence the air demand since the specific amount of feed gas must be devoted to fill up these volumes during the pressurisation step. Therefore, considering the already mentioned focus on the energy conservation issue, the effect of the adsorber and non-adsorber void volumes on PSA performance indicators was experimentally studied.

The experimental PSA test rig consists of: (1) the bottom adsorber void of app. $0.0062 \mathrm{~L}$, (2) the top adsorber void of app. $0.0068 \mathrm{~L}$, (3) the bottom non-adsorber void of app. $0.016 \mathrm{~L}$, and (4) the top non-adsorber void of app. $0.018 \mathrm{~L}$. As the single adsorber packed-bed volume equals app. $2 \mathrm{~L}$, the primary ratio of the listed system voids to the packed-bed 

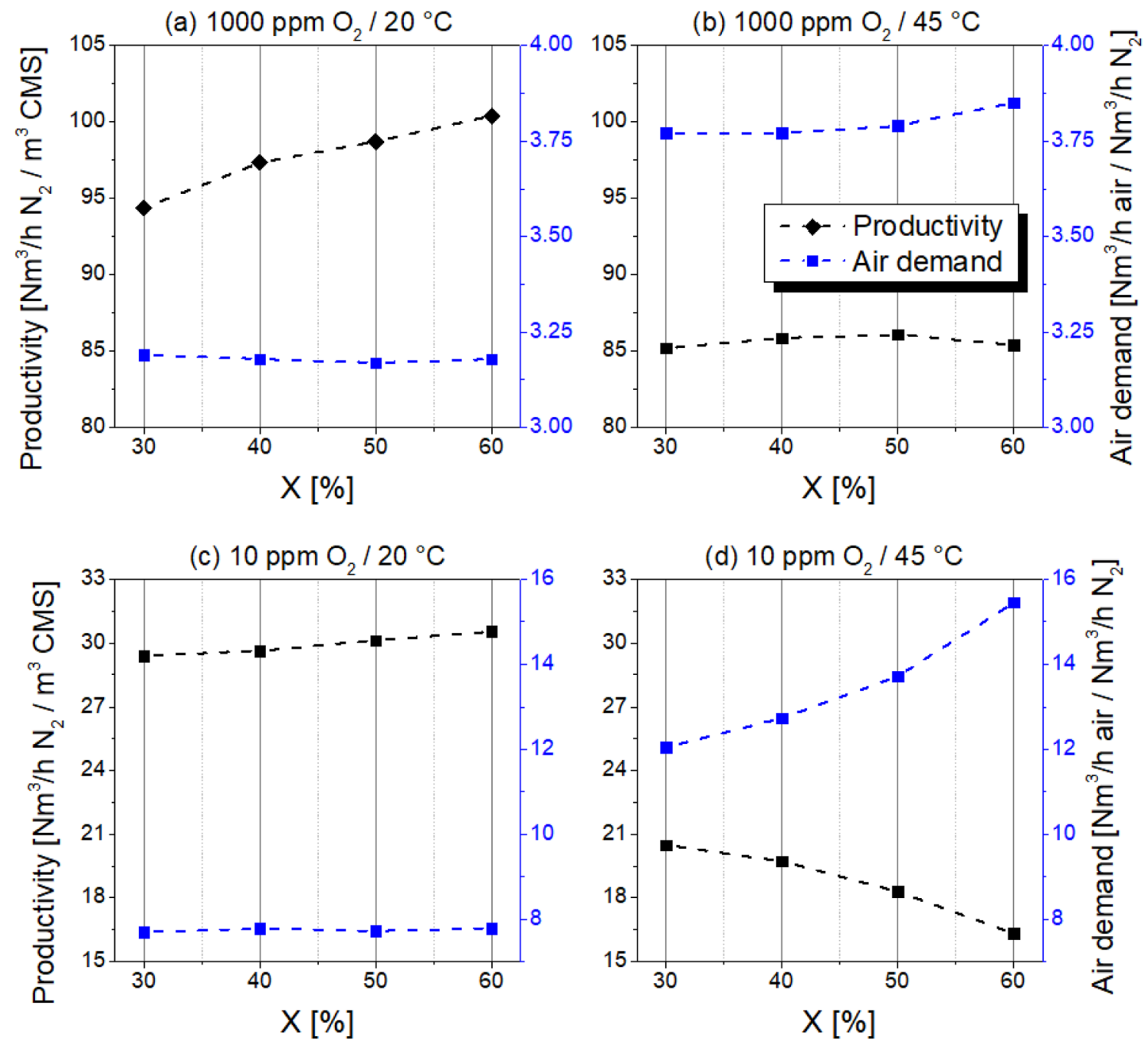

Fig. 8 PSA performance at different purge stream flow rates: $\mathbf{a}, \mathbf{b}$ at product purity of $1000 \mathrm{ppm}_{2}, \mathbf{c}, \mathbf{d}$ at product purity of 10 ppm $\mathrm{O}_{2}, \mathbf{a}, \mathbf{c}$ at operating temperature of $20^{\circ} \mathrm{C}, \mathbf{b}, \mathbf{d}$ at operating temperature of $45^{\circ} \mathrm{C}$

Table 10 PSA performance at different volume ratios of the system voids to the adsorber packed-bed volume at product purity of $1000 \mathrm{ppm} \mathrm{O}_{2}$

Table 11 PSA performance in different volume ratios of the system voids to the adsorber packed-bed volume at product purity of $10 \mathrm{ppm} \mathrm{O}_{2}$

\begin{tabular}{lllllll}
\hline $\mathrm{V}_{\text {voids }} / \mathrm{V}_{\text {adsorber }}$ & $2.35 \%$ & & $4.35 \%$ & \multicolumn{3}{c}{$6.35 \%$} \\
\hline Operating temperature $\left({ }^{\circ} \mathrm{C}\right)$ & 20 & 45 & 20 & 45 & 20 & 45 \\
Productivity $\left(\mathrm{Nm}^{3} / \mathrm{h} \mathrm{N}_{2} / \mathrm{m}^{3} \mathrm{CMS}\right)$ & 97.35 & 85.87 & 97.35 & 85.20 & 97.35 & 84.75 \\
Air demand $\left(\mathrm{Nm}^{3} / \mathrm{h}\right.$ air $\left./ \mathrm{Nm}^{3} / \mathrm{h} \mathrm{N}_{2}\right)$ & 3.18 & 3.77 & 3.20 & 3.82 & 3.22 & 3.87 \\
\hline
\end{tabular}

\begin{tabular}{lllllll}
\hline $\mathrm{V}_{\text {voids }} / \mathrm{V}_{\text {adsorber }}$ & $2.35 \%$ & & $4.35 \%$ & \multicolumn{3}{c}{$6.35 \%$} \\
\hline Operating temperature $\left({ }^{\circ} \mathrm{C}\right)$ & 20 & 45 & 20 & 45 & 20 & 45 \\
Productivity $\left(\mathrm{Nm}^{3} / \mathrm{h} \mathrm{N}_{2} / \mathrm{m}^{3} \mathrm{CMS}\right)$ & 29.64 & 19.80 & 29.64 & 19.40 & 29.64 & 19.20 \\
Air demand $\left(\mathrm{Nm}^{3} / \mathrm{h}\right.$ air $\left./ \mathrm{Nm}^{3} / \mathrm{h} \mathrm{N}_{2}\right)$ & 7.78 & 12.73 & 7.80 & 12.89 & 7.82 & 13.05 \\
\hline
\end{tabular}

volume in the investigated PSA unit equals app. $2.35 \%$. The different volume ratios of the voids to the adsorber packed-bed were accomplished by increasing exclusively the non-adsorber void volume. The adsorber void is strictly associated with a column design and cannot be varied easily in the already existing set-up. The piping extensions of the 
original internal diameter were installed symmetrically at the top and the bottom column sections, therefore no additional effect of changing the gas velocity is introduced. The results are presented in Tables 10 and 11.

As expected, at every investigated process condition an increase of the system void volume results in a slightly higher air demand. The effect is a little more pronounced at elevated operating temperature probably due to thermal expansion of the gas. Furthermore, the air demand increases slightly with an enlargement of the system voids, following a linear function. This finding indicates that the non-adsorber voids in the PSA system have no impact on the mass transfer behaviour or column dynamics since the gas velocity is not influenced. Thus, an increase of the system void volume shows no or just a negligible effect on the nitrogen productivity at every investigated process condition.

\subsection{Effect of the purge stream flow rate}

The counter-current purge is a step of the PSA cycle applied simultaneously to the counter-current blow-down, during which a specified volume of product gas is reversed into the adsorber column. The step is an element of the regeneration process of the packed-bed to reduce the amount of oxygen in the column before starting the following production step. The flow rate of the purge stream is adjusted according to Eq. 5:

$Q_{\text {purge }}=\frac{X \cdot V_{\text {adsorber }}}{t_{\text {purge }}}$

where: $Q_{\text {purge }}$ is the flow rate of the purge stream $\left(\mathrm{Nm}^{3} / \mathrm{h}\right)$, $\mathrm{V}_{\text {adsorber }}$ is the volume of the packed-bed $\left(\mathrm{m}^{3}\right), \mathrm{t}_{\text {purge }}$ is time of the purge step (h), and $\mathrm{X}$ is a proportionality factor [-]. The magnitude of the proportionality factor $\mathrm{X}$ can be associated with the packed-bed porosity as it exhibits the adsorber volume fraction occupied by oxygen-enriched desorption gas which should be replaced by nitrogen-enriched product gas. However, this coarse approximation of $\mathrm{X}$ not always results in the improved process performance since the suitable amount of the purge gas significantly influences the concentration profiles along the adsorber length. Therefore, the effect of the purge stream flow rate on the PSA performance indicators was experimentally studied. The results are presented in Tables 12 and 13 and Fig. 8.

At a low operating temperature level $\left(20^{\circ} \mathrm{C}\right)$ an increased purge flow rate into the system ensures elevated nitrogen productivity values regardless of the investigated purity level. The efficiency of the desorption process is diminished as the operating temperature decreases so that an additional reinforcement in the form of the oxygen expulsion from the packed-bed void volume by the nitrogen purge stream is required in order to regenerate the adsorber bed properly. The effect is more pronounced at a low product purity level $\left(1000 \mathrm{ppm} \mathrm{O}_{2}\right)$ rather than at a high product purity level $\left(10 \mathrm{ppm} \mathrm{O}_{2}\right)$ due to the extended oxygen MTZ in the adsorber column which is caused by the high gas superficial velocity and therefore intensified axial mass dispersion. Since the air demand remains rather insensitive to the change of the purge flow rate, it is recommended to operate the PSA unit with an increased purge stream flow rate wherever the process conditions are corresponding.

On the contrary, at a high operating temperature level $\left(45^{\circ} \mathrm{C}\right)$ an increased purge flow rate into the system causes lower nitrogen productivity values when the high-purity product is generated. It indicates that the proper regeneration of the adsorbent packed-bed with a narrow mass transfer zone is accomplished already at the lowest investigated value of the purge flow rate. Here, the thermodynamic effect comes to the fore as the desorption process is promoted at elevated operating temperatures. Therefore, any enlargement of the purge stream flow rate results in the dissipation of the product gas; consequently, the air demand boosts up largely. When the low-purity product is generated, a
Table 12 PSA performance at different purge stream flow rates at product purity of $1000 \mathrm{ppm}$ $\mathrm{O}_{2}$

\begin{tabular}{lllllllll}
\hline $\mathrm{X}$ & $30 \%$ & & $40 \%$ & \multicolumn{3}{c}{$50 \%$} & \multicolumn{3}{c}{$60 \%$} \\
Purge flow rate $\left(\mathrm{Nm}^{3} / \mathrm{h}\right)$ & 0.0364 & & 0.0485 & & 0.0606 & \multicolumn{3}{c}{0.0727} \\
Operating temperature $\left({ }^{\circ} \mathrm{C}\right)$ & 20 & 45 & 20 & 45 & 20 & 45 & 20 & 45 \\
Productivity $\left(\mathrm{Nm}^{3} / \mathrm{h} \mathrm{N}_{2} / \mathrm{m}^{3} \mathrm{CMS}\right)$ & 94.35 & 85.20 & 97.35 & 85.87 & 98.70 & 86.10 & 100.4 & 85.42 \\
Air demand $\left(\mathrm{Nm}^{3} / \mathrm{h}\right.$ air $\left./ \mathrm{Nm}^{3} / \mathrm{h} \mathrm{N}_{2}\right)$ & 3.19 & 3.77 & 3.18 & 3.77 & 3.17 & 3.79 & 3.18 & 3.85 \\
\hline
\end{tabular}

\begin{tabular}{lllllllll}
\hline $\mathrm{X}$ & $30 \%$ & & $40 \%$ & \multicolumn{3}{c}{$50 \%$} & \multicolumn{3}{c}{$60 \%$} & \\
Purge flow rate $\left(\mathrm{Nm}^{3} / \mathrm{h}\right)$ & 0.0364 & & 0.0485 & & 0.0606 & \multicolumn{2}{c}{0.0727} & \\
Operating temperature $\left({ }^{\circ} \mathrm{C}\right)$ & 20 & 45 & 20 & 45 & 20 & 45 & 20 & 45 \\
Productivity $\left(\mathrm{Nm}^{3} / \mathrm{h} \mathrm{N}_{2} / \mathrm{m}^{3} \mathrm{CMS}\right)$ & 29.40 & 20.50 & 29.64 & 19.80 & 30.12 & 18.30 & 30.55 & 16.33 \\
Air demand $\left(\mathrm{Nm}^{3} / \mathrm{h}\right.$ air $\left./ \mathrm{Nm}^{3} / \mathrm{h} \mathrm{N}_{2}\right)$ & 7.70 & 12.04 & 7.78 & 12.73 & 7.73 & 13.72 & 7.78 & 15.45 \\
\hline
\end{tabular}

Table 13 PSA performance at different purge stream flow rates at product purity of $10 \mathrm{ppm} \mathrm{O}_{2}$ 

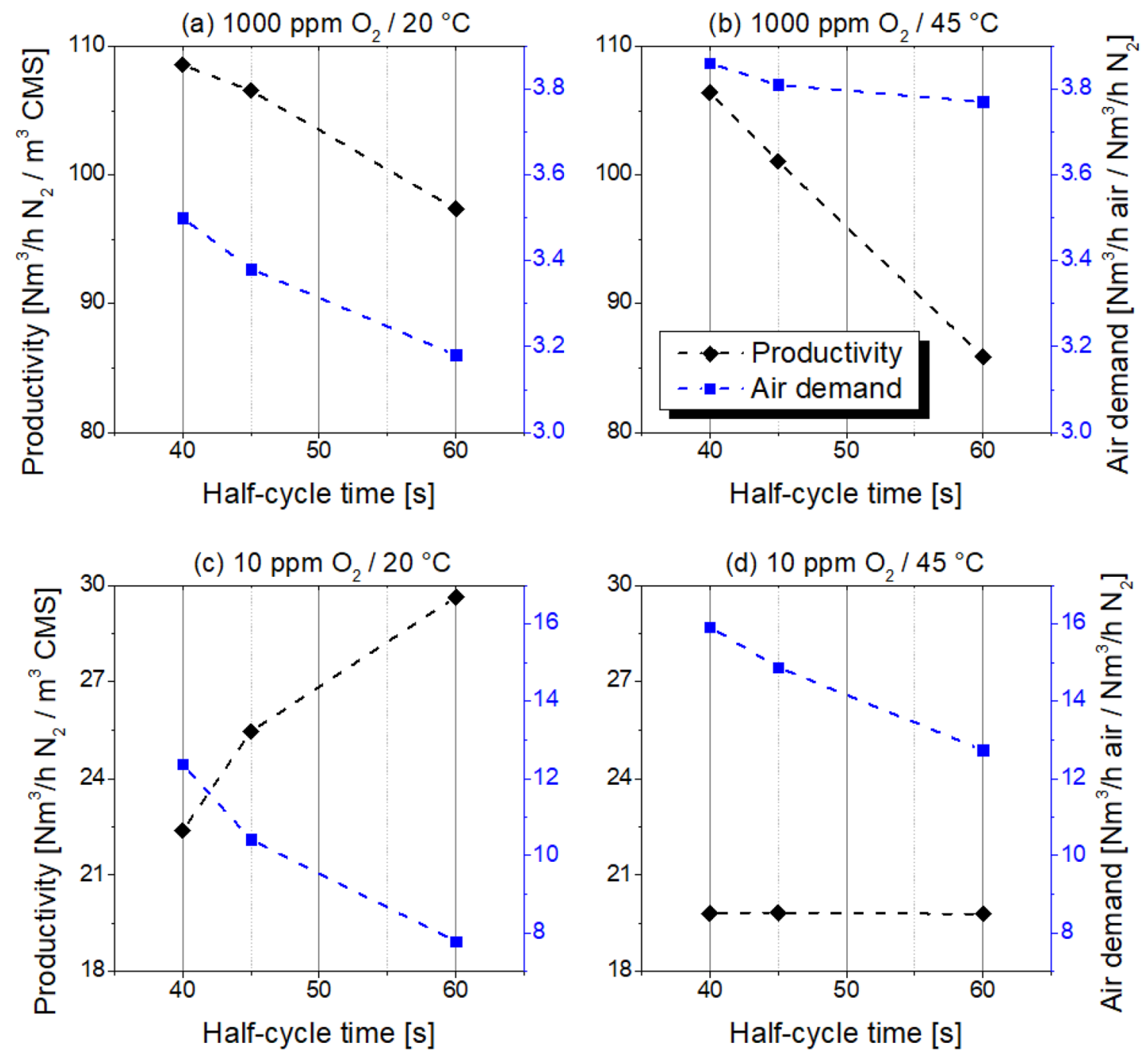

Fig. 9 PSA performance at different half-cycle times: $\mathbf{a}, \mathbf{b}$ at product purity of $1000 \mathrm{ppm} \mathrm{O}_{2}, \mathbf{c}, \mathbf{d}$ at product purity of 10 ppm $\mathrm{O}_{2}, \mathbf{a}, \mathbf{c}$ in operating temperature of $20^{\circ} \mathrm{C}, \mathbf{b}, \mathbf{d}$ in operating temperature of $45^{\circ} \mathrm{C}$

competition between the requirement of intensified purging of the packed-bed with an extended oxygen MTZ on one side, and the saving of the product gas on the other side, can be found. At the proportionality factor value of $40 \%$ the highest productivity is achieved with the lowest air demand value at the same time.

\subsection{Effect of the half-cycle time}

The proper estimation of the contact time of gas and solid phases is of essential importance in the case of kinetically controlled separations. Excessively prolonged duration of adsorption diminishes separation selectivity by approaching the thermodynamic equilibrium state. On the other hand, too short adsorption is not beneficial either since diffusivity
Table 14 PSA performance at different half-cycle times at product purity of $1000 \mathrm{ppm} \mathrm{O}_{2}$

\begin{tabular}{lllllll}
\hline Half-cycle time $(\mathrm{s})$ & 60 & & 45 & & 40 \\
Purge time (s) & 59 & & 44 & & 39 & \\
Purge flow rate $\left(\mathrm{Nm}^{3} / \mathrm{h}\right)$ & 0.0485 & & 0.0650 & & 0.0733 & \\
Operating temperature $\left({ }^{\circ} \mathrm{C}\right)$ & 20 & 45 & 20 & 45 & 20 & 45 \\
Productivity $\left(\mathrm{Nm}^{3} / \mathrm{h} \mathrm{N}_{2} / \mathrm{m}^{3} \mathrm{CMS}\right)$ & 97.35 & 85.87 & 106.55 & 101.05 & 108.54 & 106.39 \\
Air demand $\left(\mathrm{Nm}^{3} / \mathrm{h}^{2}\right.$ air $\left./ \mathrm{Nm}^{3} / \mathrm{h} \mathrm{N}_{2}\right)$ & 3.18 & 3.77 & 3.38 & 3.81 & 3.50 & 3.86 \\
\hline
\end{tabular}


Table 15 PSA performance at different half-cycle times at product purity of $10 \mathrm{ppm} \mathrm{O}_{2}$

\begin{tabular}{|c|c|c|c|c|c|c|}
\hline Half-cycle time (s) & 60 & & 45 & & 40 & \\
\hline Purge time (s) & 59 & & 44 & & 39 & \\
\hline Purge flow rate $\left(\mathrm{Nm}^{3} / \mathrm{h}\right)$ & 0.0485 & & 0.0650 & & 0.0733 & \\
\hline Operating temperature $\left({ }^{\circ} \mathrm{C}\right)$ & 20 & 45 & 20 & 45 & 20 & 45 \\
\hline Productivity $\left(\mathrm{Nm}^{3} / \mathrm{h} \mathrm{N}_{2} / \mathrm{m}^{3} \mathrm{CMS}\right)$ & 29.64 & 19.80 & 25.46 & 19.82 & 22.38 & 19.81 \\
\hline Air demand $\left(\mathrm{Nm}^{3} / \mathrm{h}\right.$ air $\left./ \mathrm{Nm}^{3} / \mathrm{h} \mathrm{N}_{2}\right)$ & 7.78 & 12.73 & 10.42 & 14.88 & 12.37 & 15.92 \\
\hline
\end{tabular}

Fig. 10 Experimental pressure profiles of adsorber columns at different cutting times: a $0 \mathrm{~s}$, b $5 \mathrm{~s}, \mathrm{c} 10 \mathrm{~s}, \mathbf{d} 15 \mathrm{~s}$ (a)

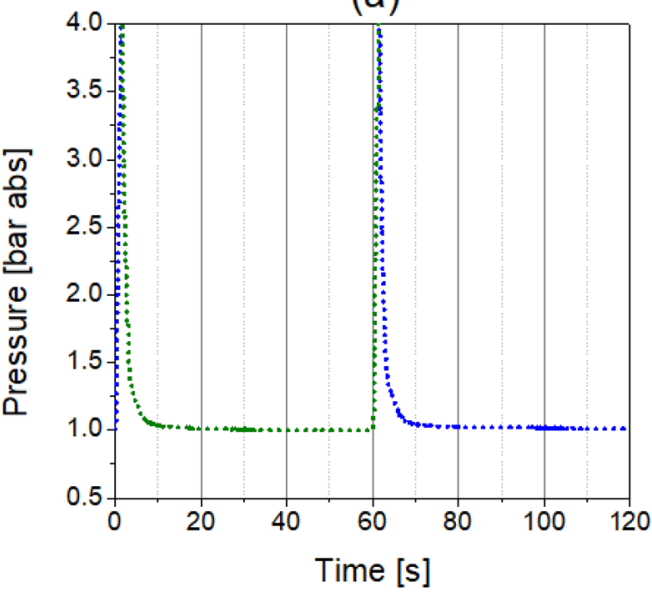

(c)

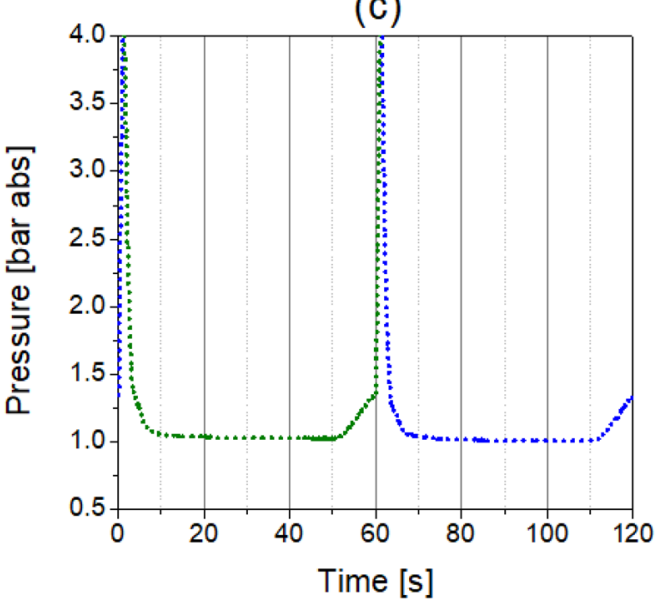

(b)

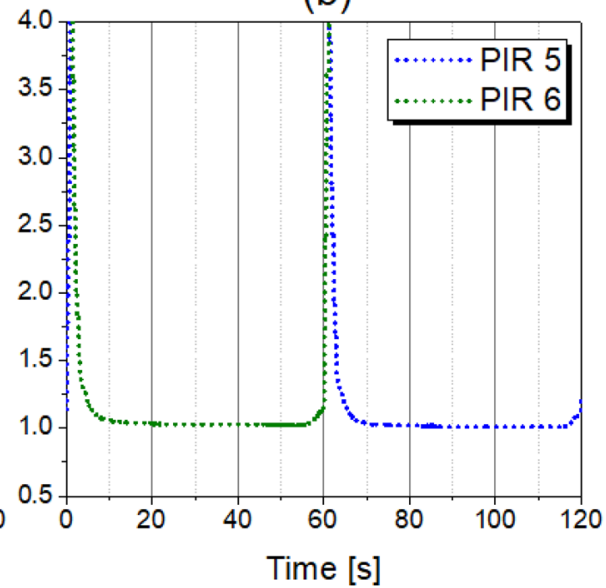

(d)

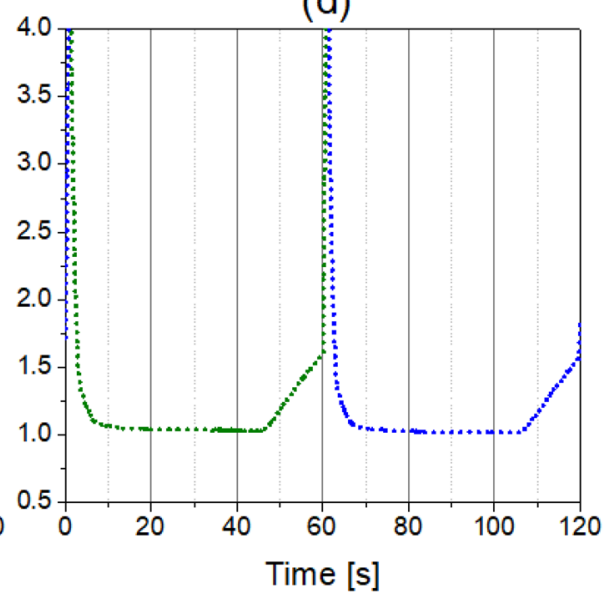

limitations occur. Therefore, the existence of an optimal contact time of phases is expected which greatly depends on applied process conditions i.e. operating temperature and gas pressure. In the PSA systems, additional effects of the mass axial dispersion and the pressure drop along the fixed-bed should be taken into consideration since the modification of a half-cycle time changes the time span proportion of pressurisation and production steps. Therefore, the consequences of those effects e.g. premature column breakthrough or reduced working pressure are more pronounced as the halfcycle time is shortened. However, in industrial practice brief cycle times are aimed in order to increase the number of cycles per hour of PSA operation and thus boost-up nitrogen productivity. For that reason, the effect of the half-cycle time on PSA performance indicators was experimentally studied. The results are presented in Tables 14, 15 and Fig. 9. Experiments were performed with the value of the proportionality factor X (see Eq. 1) equals $40 \%$. 
When the low-purity $\left(1000 \mathrm{ppm} \mathrm{O}_{2}\right)$ product is generated the productivity increases as the half-cycle time is shortened. This finding confirms that the multiplication of the number of cycles per hour brings benefits for the process performance as the kinetic selectivity is more exploited. Thus, the premature breakthrough of adsorbent fixed-bed does not occur even at relatively high gas superficial velocity and thus extended oxygen MTZ. By the reduction of half-cycle time to $40 \mathrm{~s}$, productivity is increased by $11.5 \%$. The effect is more pronounced at a high operating temperature level $\left(45^{\circ} \mathrm{C}\right)$ due to a higher rate of mass transfer-in this case, productivity is increased by $23.9 \%$.

However, the opposite effect is found when the highpurity $\left(10 \mathrm{ppm} \mathrm{O}_{2}\right)$ product is generated. In that case, the productivity decreases as the half-cycle time is shortened at a low operating temperature level $\left(20^{\circ} \mathrm{C}\right)$. It means that either the time provided for a mass transfer is insufficient and thus the diffusivity limit was encountered; or a premature column breakthrough occurs due to axial dispersion effects during the pressurisation step. Nevertheless, the observation could also be explained as a combination of both effects. The productivity is insensitive to manipulation of half-cycle time at a high operating temperature level $\left(45^{\circ} \mathrm{C}\right)$ which indicates the compensated effects of faster mass transfer kinetics on one side and premature column breakthrough on the other side.

At every investigated process condition, the reduction of the half-cycle time results in an increased air demand due to the aforementioned change of time proportion for the different steps in the cycle. The adjustment of short half-cycle times makes the pressurisation step more significant in relation to the production step. Since the specific volume of compressed air is required to achieve the operating pressure level, a smaller amount of compressed air is utilised for the production purpose at a short half-cycle time in comparison to a long half-cycle time. Consequently, at shortened halfcycle time the air demand is higher in order to maintain the targeted purity of the product. The greatest air demand enhancement is observed when the high-purity $\left(10 \mathrm{ppm} \mathrm{O}_{2}\right)$ product is generated at a low operating temperature level $\left(20^{\circ} \mathrm{C}\right)$.

\subsection{Effect of the cutting time}

The cutting step is a supplementary cycle design element implemented at the end of the PSA cycle terminating the blow-down and purge steps before finishing the adsorption step in the neighbour column. Cutting can be adapted in
Fig. 11 PSA performance at different cutting times: $\mathbf{a}, \mathbf{b}$ at product purity of $1000 \mathrm{ppm} \mathrm{O}_{2}$, $\mathbf{c}, \mathbf{d}$ at product purity of $10 \mathrm{ppm}$ $\mathrm{O}_{2}, \mathbf{a}, \mathbf{c}$ in operating temperature of $20^{\circ} \mathbf{C}, \mathbf{b}, \mathbf{d}$ in operating temperature of $45^{\circ} \mathrm{C}$ (a) $1000 \mathrm{ppm} \mathrm{O} / 20^{\circ} \mathrm{C}$

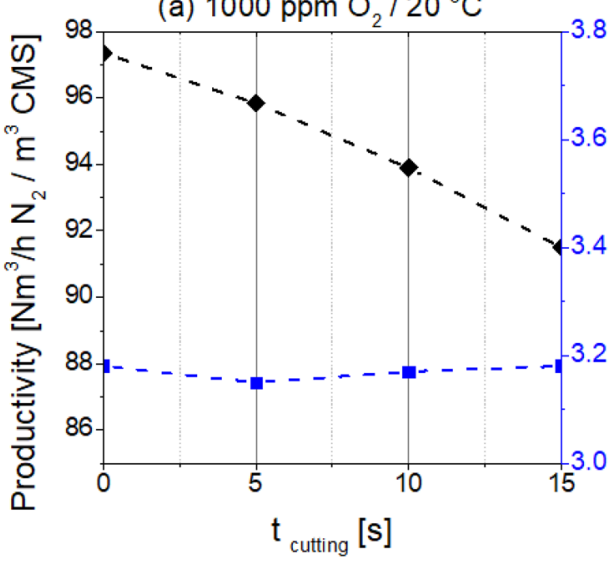

(c) $10 \mathrm{ppm} \mathrm{O} / 20^{\circ} \mathrm{C}$

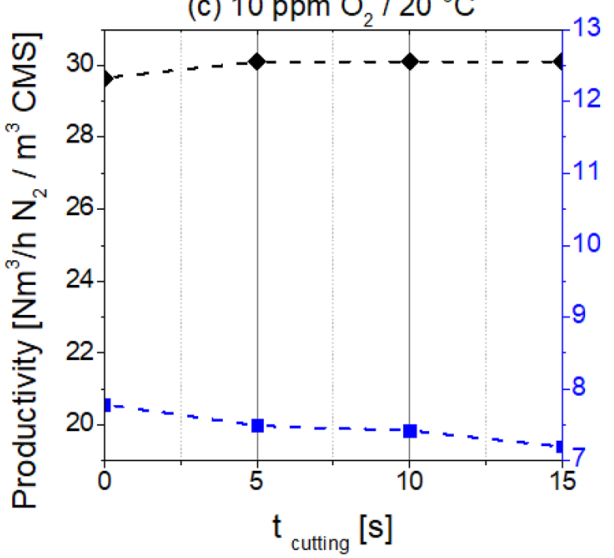

(b) $1000 \mathrm{ppm} \mathrm{O} / 45^{\circ} \mathrm{C}$

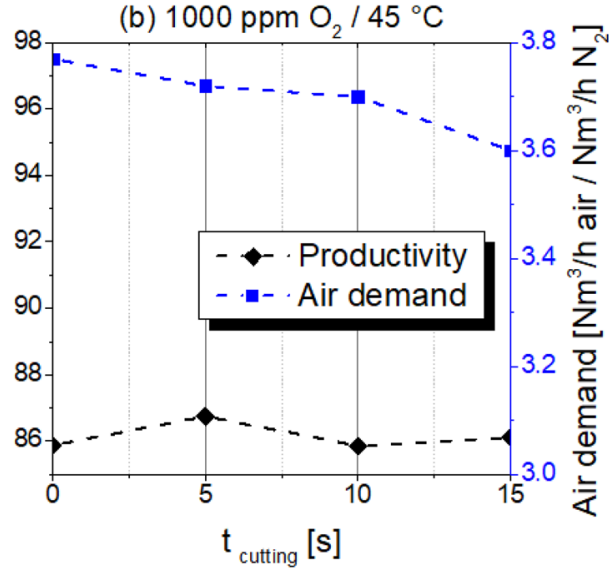

(d) $10 \mathrm{ppm} \mathrm{O} / 45^{\circ} \mathrm{C}$

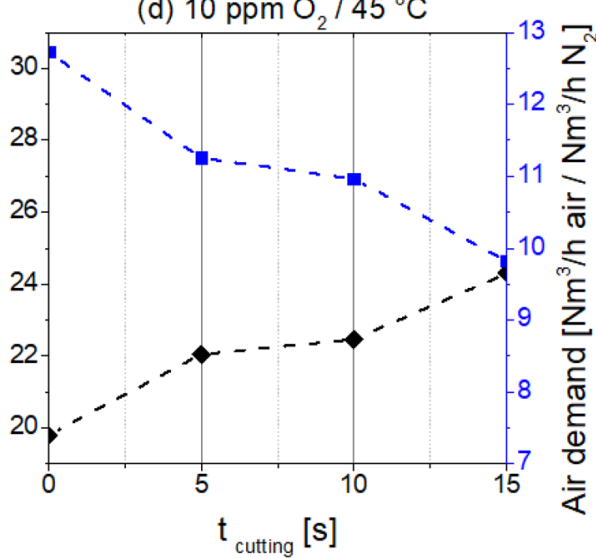


Table 16 PSA performance at different cutting times at product purity of $1000 \mathrm{ppm}_{2}$

\begin{tabular}{|c|c|c|c|c|c|c|c|c|}
\hline Cutting time (s) & \multicolumn{2}{|l|}{0} & \multicolumn{2}{|l|}{5} & \multicolumn{2}{|l|}{10} & \multicolumn{2}{|l|}{15} \\
\hline Purge time (s) & 59 & & 54 & & 49 & & 44 & \\
\hline Purge flow rate $\left(\mathrm{Nm}^{3} / \mathrm{h}\right)$ & 0.0485 & & 0.0530 & & 0.0584 & & 0.0650 & \\
\hline Operating temperature $\left({ }^{\circ} \mathrm{C}\right)$ & 20 & 45 & 20 & 45 & 20 & 45 & 20 & 45 \\
\hline Productivity $\left(\mathrm{Nm}^{3} / \mathrm{h} \mathrm{N}_{2} / \mathrm{m}^{3} \mathrm{CMS}\right)$ & 97.35 & 85.87 & 95.85 & 86.75 & 93.90 & 85.85 & 91.50 & 86.10 \\
\hline Air demand $\left(\mathrm{Nm}^{3} / \mathrm{h}\right.$ air $\left./ \mathrm{Nm}^{3} / \mathrm{h} \mathrm{N}_{2}\right)$ & 3.18 & 3.77 & 3.15 & 3.72 & 3.17 & 3.70 & 3.18 & 3.60 \\
\hline Tail-gas $\mathrm{O}_{2}$ concentration [vol.- $\%$ ] & 30.57 & 28.35 & 30.54 & 28.58 & 30.50 & 28.61 & 30.53 & 28.93 \\
\hline
\end{tabular}

Table 17 PSA performance at different cutting times at product purity of $10 \mathrm{ppm}_{2}$

\begin{tabular}{|c|c|c|c|c|c|c|c|c|}
\hline Cutting time (s) & 0 & & 5 & & 10 & & 15 & \\
\hline Purge time (s) & 59 & & 54 & & 49 & & 44 & \\
\hline Purge flow rate $\left(\mathrm{Nm}^{3} / \mathrm{h}\right)$ & 0.0485 & & 0.0530 & & 0.0584 & & 0.0650 & \\
\hline Operating temperature $\left({ }^{\circ} \mathrm{C}\right)$ & 20 & 45 & 20 & 45 & 20 & 45 & 20 & 45 \\
\hline Productivity $\left(\mathrm{Nm}^{3} / \mathrm{h} \mathrm{N}_{2} / \mathrm{m}^{3} \mathrm{CMS}\right)$ & 29.64 & 19.80 & 30.10 & 22.05 & 30.10 & 22.46 & 30.10 & 24.30 \\
\hline Air demand $\left(\mathrm{Nm}^{3} / \mathrm{h}\right.$ air $\left./ \mathrm{Nm}^{3} / \mathrm{h} \mathrm{N}_{2}\right)$ & 7.78 & 12.73 & 7.49 & 11.25 & 7.42 & 10.96 & 7.20 & 9.82 \\
\hline Tail-gas $\mathrm{O}_{2}$ concentration [vol.- $\%$ ] & 24.11 & 22.71 & 24.18 & 22.94 & 24.26 & 22.97 & 24.28 & 23.26 \\
\hline
\end{tabular}

order to improve the PSA process performance of kineticbased separation since the difference in the sorption rates of molecules in the feed gas mixture can be exploited. Whereas the duration of the blow-down step is reduced, the desorption of gases from the CMS adsorbent could still progress while the adsorber column is not opened to the ambient. The effect is more pronounced for components with slow mass transfer kinetics due to insufficient time provided for its complete desorption from the adsorbent surface. Since nitrogen is the component with slow kinetics, it is expected that losses of adsorbed nitrogen to the wasted tail-gas can be avoided. Consequently, the system pressure at the end of the PSA cycle increases, as presented in Fig. 10, which could possibly diminish the air demand values without a premature breakthrough of the fast-adsorbing component.

In practice, the cutting time is set by finding analytically that time point at which the oxygen concentration undercuts the concentration level of ambient air at the adsorber exit. This procedure prevents avoidable nitrogen losses and helps to get a low air demand. Generally, cutting is not considered for the PSA reference process, since the optimal placement of this step depends on the CMS properties and cannot be fixed independently from the selected CMS-type or even CMS-lot [14]. Besides, analogously to the previously discussed case of changing the purge stream flow rate in the PSA system, also the implementation of a cutting step impacts the oxygen mass transfer zone along the adsorber during production and regeneration; thus, its adoption greatly depends on the process conditions. Therefore, the effect of the duration of the cutting step on the PSA performance indicators was experimentally studied. The results are presented in Tables 16, 17 and Fig. 11. Experiments were performed with the value of the proportionality factor $\mathrm{X}$ (see Eq. 1) equals $40 \%$.
When the high-purity $\left(10 \mathrm{ppm} \mathrm{O}_{2}\right)$ product is generated at a high operating temperature level $\left(45^{\circ} \mathrm{C}\right)$ implementation of the cutting step brings the greatest benefit for the process performance. The productivity increases and the air demand decreases significantly as the cutting time is prolonged. By means of implementing a $15 \mathrm{~s}$ cutting step the productivity increases by $22.73 \%$ and the air demand decreases by $22.86 \%$ in relation to the process without cutting. It indicates that the oxygen desorption occurs in the initial phase of the blow-down and the purge steps, respectively, so the packed-bed with a narrow mass transfer zone is regenerated, especially at elevated operating temperatures. Moreover, the mean oxygen concentration in the tail-gas escalates when the cutting time is prolonged so that the tail-gas becomes less diluted by nitrogen. It signifies that the desorption of nitrogen progresses during the cutting step which ensures lower oxygen concentration in the adsorber column at the beginning of the following production step and also a higher initial pressure in the system.

On the contrary, at a low operating temperature level $\left(20^{\circ} \mathrm{C}\right)$ an implementation of the cutting step causes lower nitrogen productivity values when the low-purity (1000 ppm $\mathrm{O}_{2}$ ) product is generated. It indicates that an insufficient amount of time was provided for a desorption of oxygen which forms a wide MTZ along the adsorber. Consequently, the packed-bed is not properly regenerated before the following production step, and the premature oxygen breakthrough occurs. Since the air demand remains rather insensitive to the cutting time, it is recommended to operate the PSA unit without the adoption of cutting wherever the process conditions are corresponding.

For other investigated process conditions it can be noticed that the mean oxygen concentration in the tail-gas increases as the cutting time is prolonged which consequently results 
in lower air demand together with rather stable productivity values.

\section{Conclusions}

Process intensification strategies for high-purity twin-bed PSA with a focus on the PSA unit configuration and cycle organisation were introduced and discussed. Effects of the flow resistances in the piping system including equalisation trim, the nitrogen receiver volume, the system void volumes, the purge stream flow rate, the half-cycle time, and the adoption of cutting step on the separation process performance were studied. Recommendations for improving the process performance with a particular emphasis on the reduction of energy consumption were given based on the experimental research at two product purity levels and two operating temperatures. On one hand, it was clearly shown that measures associated with the PSA configuration, which properly manage the flow resistances in the piping system, the volume of the product receiver tank, and the system void volumes result in increased productivity and reduced air demand numbers regardless of the required purity level or operating temperature. On the other hand, the optimal cycle organisation is strictly related to the ambient temperature and the required purity level-their effect on the performance indicators are much more pronounced in high-purity rather than in low-purity PSA plants.

Acknowledgements This experimental research was generously supported by CarboTech AC GmbH, Essen, Germany. We gratefully thank Mr. Daniel Böke and Mr. Carsten Schledorn for their espousal.

Funding Open Access funding enabled and organized by Projekt DEAL.

Open Access This article is licensed under a Creative Commons Attribution 4.0 International License, which permits use, sharing, adaptation, distribution and reproduction in any medium or format, as long as you give appropriate credit to the original author(s) and the source, provide a link to the Creative Commons licence, and indicate if changes were made. The images or other third party material in this article are included in the article's Creative Commons licence, unless indicated otherwise in a credit line to the material. If material is not included in the article's Creative Commons licence and your intended use is not permitted by statutory regulation or exceeds the permitted use, you will need to obtain permission directly from the copyright holder. To view a copy of this licence, visit http://creativecommons.org/licenses/by/4.0/.

\section{References}

1. Castle, W.F.: Air separation and liquefaction: recent developments and prospects for the beginning of the new millennium. Int. J. Refrig 25, 158-172 (2002)

2. Shirley, A.I., Lemcoff, N.O.: Air Separation by Carbon Molecular Sieves. Adsorption 8, 147-155 (2002)

3. Patel, S.V., Patel, J.M.: Separation of High Purity Nitrogen from Air by Pressure Swing Adsorption on Carbon Molecular Sieves. International Journal of Engineering Research \& Technology (IJERT) 3, 450-454 (2014)

4. Vemula, R.R., Kothare, M.V., Sircar, S.: Anatomy of a rapid pressure swing adsorption process performance. AIChE J. 61, 2008-2015 (2015)

5. Smith, A.R., Klosek, J.: A review of air separation technologies and their integration with energy conversion processes. Fuel Process. Technol. 70, 115-134 (2001)

6. P. Froehlich, A Sustainable Approach to the Supply of Nitrogen, 2013.

7. Moulijn, J.A., Stankiewicz, A., Grievink, J., Górak, A.: Process intensification and process systems engineering: A friendly symbiosis. Comput. Chem. Eng. 32, 3-11 (2008)

8. Luberti, M., Friedrich, D., Brandani, S., Hyungwoong, A.: Design of a H2 PSA for cogeneration of ultrapure hydrogen and power at an advanced integrated gasification combined cycle with precombustion capture. Adsorption 20, 511-524 (2014)

9. Santos, M.S., Grande, C.A., Rodrigues, A.E.: New cycle configuration to enhance performance of kinetic PSA processes. Chem. Eng. Sci. 66, 1590-1599 (2011)

10. Bhatt, T.S., Storti, G., Denayer, J.F.M., Rota, R.: Equilibrium Theory-Based Assessment of Dual-Reflux Pressure Swing Adsorption Cycles That Utilize Light Gas for Pressure Swing. Ind. Eng. Chem. Res. 58, 350-365 (2019)

11. Esteves, I.A.A.C., Mota, J.P.B.: Simulation of a new hybrid membrane/pressure swing adsorption process for gas separation. Desalination 148, 275-280 (2002)

12. Rota, R., Wankat, P.C.: Intensification of Pressure Swing Adsorption Processes. AIChE J. 36, 1299-1312 (1990)

13. Jasra, R.V., Choudary, N.V., Bhat, S.G.T.: Separation of Gases by Pressure Swing Adsorption. Sep. Sci. Technol. 26, 885-930 (1991)

14. A. Marcinek, J. Guderian, D. Bathen, Performance determination of high-purity N2-PSA-plants, Adsorption (2020).

15. Pan, C.Y., Basmadjian, D.: An analysis of adiabatic sorption of single solutes in fixed beds: pure thermal wave formation and its practical implications. Chem. Eng. Sci. 25, 1653-1664 (1970)

16. Kim, Y.H., Lee, D.G., Moon, D.K., Byeon, S.-H., Ahn, H.W., Lee, C.H.: Effect of bed void volume on pressure vacuum swing adsorption for air separation. Korean J. Chem. Eng. 31, 132-141 (2014)

Publisher's Note Springer Nature remains neutral with regard to jurisdictional claims in published maps and institutional affiliations. 